\title{
A FUZZY MULTI-CRITERIA DECISION MAKING METHODOLOGY BASED UPON THE INTERVAL TYPE-2 FUZZY SETS FOR EVALUATING RENEWABLE ENERGY ALTERNATIVES IN TURKEY
}

\author{
Abit BALIN, Hayri BARAÇLI \\ Department of Industrial Engineering, Yildiz Technical University, Besiktas Istanbul, 34000,Turkey
}

Received 03 December 2013; accepted 31 August 2014

\begin{abstract}
Energy is substantial for social development and has an essential role for the survival and development of human as an environmental factor. Due to the serious increase ofthe world's primary energy price and rapid development of Turkey's economy, energy consumption of Turkey has become a major problem. For that purpose, opinions of the decision makers upon the relative importance of selection criteria are determined by using a fuzzy AHP procedure based upon type- 2 fuzzy sets, and fuzzy multi-criteria decision-making based upon the interval type-2 TOPSIS method is used to rank the best renewable alternative energy. In this paper, a fuzzy multi criteria decision making (MCDM) methodology was proposed to determine the best renewable energy alternatives for Turkey, because type-2 fuzzy sets provide additional degrees of independence to represent the uncertainty and the fuzziness of real world applications. The results showed that wind was the best alternative for Turkey's energy investments, as being followed subsequently by solar, biomass, geothermal, hydraulic and hydrogen. The results were based upon the opinions of three energy planning experts who ranked the energy alternatives according to the ten criteria we have selected.
\end{abstract}

Keywords: renewable energy, Type-2 fuzzy sets, MCDM, TOPSIS, AHP.

JEL Classification: D81, Q42, O13.

\section{Introduction}

Energy system plays an important role in the economic and social development of a country and the life quality of people. Some new governmental policies have been adopted to encourage the introduction of energy efficiency measures, the technical changes, and the use of renewable and sustainable energy. Renewable energy sources have been important for humans since the beginning of civilization. Clean, domestic, and renewable energy is commonly accepted as the key for future life. Renewable energy sources are also often called alternative sources of energy. Renewable energy sources that utilize the domestic

Corresponding author Abit Balin

E-mail: abitbalin@hotmail.com 
resources have the potential to provide energy services with almost zero emission of greenhouse gases. Main renewable energy sources are biomass energy, hydro energy, geothermal energy, solar energy, and wind energy. Making an energy planning decision involves a process of balancing diverse ecological, social, technical, and economic aspects in time. This balance is critical for the survival of nature and prosperity of energy-dependent nations (Kaygusuz 2002; Soytas, Sari 2006; Abulfotuh 2007; Yuan et al. 2008; Demirbas 2008).

When we try to choose an alternative using some criteria, we have to take into account the conflicting issues among the considered criteria. The selection among the renewable energy alternatives is a multi-criteria decision making (MCDM) problem with many conflicting criteria. We have to evaluate some alternatives by considering their advantages and disadvantages based on the selection criteria. By the way, energy assessments must deal with qualities that are difficult to define and components that can involve both quantitative and qualitative factors. Hence, this problem should be overcome by a MCDM method. The methods can provide solutions to increase complex energy management problems (Kahraman et al. 2009; Wang et al. 2009; Kaya, Kahraman 2010).

During the 1970s, it was popular to deal with the energy problems by single-criterion approaches which aimed to identify the most efficient supply options at a low cost. However, in the 1980s, growing environmental awareness changed the decision framework. The need to combine the environmental and social considerations in energy planning resulted in the increasing use of multi-criteria approaches. The MCDM methods have been widely applied to social, economic, agricultural, industrial, ecological, and biological systems in addition to the energy systems (Samouilidis, Mitropoulos 1982; Pohekar, Ramachandran 2004; Chang et al. 2008; Kaya, Kahraman 2010).

In many decision making problems, the decision maker's (DM) judgments are not definite and it is relatively difficult for the decision maker to present specific numerical values for the criteria and qualities. In order to model this kind of uncertainty in human preferences, the fuzzy set theory is employed very successfully. This theory was introduced by Zadeh (1965) to express the linguistic terms in decision-making process in order to resolve the vagueness, ambiguity, and subjectivity of human judgment (Kahraman et al. 2009).

In recent years, some methods have been presented for handling fuzzy multiple-criteria group decision-making problems. Generally these methods are based upon type- 1 fuzzy sets. Since, T2FSs are more capable than ordinary fuzzy sets in handling the imprecision and imperfect information in real-world applications, new fuzzy MCDM methodology based upon type- 2 fuzzy sets was proposed for energy decision making problem in this paper. A type-2 fuzzy set (T2FS) is a membership function represented by an interval fuzzy set $[0,1]$. T2FS contain membership values that are crisp intervals and are the most widely used of the higher order fuzzy sets because of their relative simplicity (Zadeh 1965, 1975; Wu, Mendel 2007b; Aisbett et al. 2011; Chen 2013a).

In this project, we will focus on renewable energy alternatives in Turkey. Although, Turkey has abundant renewable energy resources, these resources have not been utilized enough. Turkey which has still been extensively dependent on importing the energy from foreign countries as it was in the past can only meet about one third of its total energy demand. As fossil fuel energy becomes scarcer, Turkey will most probably be faced with 
energy shortages, high energy prices, and energy insecurity within the next few decades. Moreover, Turkey's reliance on fossil fuel consumption will increase the global warming and reduce the domestic environmental quality. For these reasons, the development and use of renewable energy sources and technologies in Turkey are increasingly becoming vital for the sustainable economic development of the country (Tsabadze 2006; Wu, Chen 2007).

In this paper, we extended the AHP and TOPSIS methodologies to suggest a new method for discussing the fuzzy MCDM problems based upon T2FSs in order to evaluate renewable energy alternatives for Turkey. In this suggested methodology, the decision makers' opinions on the relative importance of the selection criteria were determined by using a fuzzy AHP; and a fuzzy TOPSIS method was used to evaluate the alternatives based upon T2FSs. The proposed method discussed fuzzy MCDM problems in a more flexible and more intelligent manner due to the fact that it used IT2FSs rather than type- 1 fuzzy sets to represent the evaluating values and the weights of attributes.

The rest of this paper is organized as follows. In Section 1, a literature review on multicriteria energy decision making was briefly given. In Section 2, the definitions of interval type-2 fuzzy sets were reviewed. In Section 3 and 4, the AHP and TOPSIS methodologies based upon IT2FSs were introduced and explained in details. In section 5, a real case application for Turkey was performed. The conclusion and further research suggestions were discussed in the final section.

\section{Literature review}

Renewable energy sources are the fastest growing energy sources in the world. In this literature, it is easy to see many MCDM papers in energy decision making. In this sub-section, these were briefly summarized as follows.

Pohekar and Ramachandran (2004) presented a review of the implementation of MCDM techniques in energy planning and management. Zhou et al. (2006) reviewed the literature about decision analysis in energy based environmental studies. Erdogmus et al. (2006) tried to determine the most suitable fuel that could be used for residential heating using the Analytical Network Process (ANP). Terrados et al. (2007) focused on operating a strategic plan about the renewable resources, mainly solar and biomass energy, in a province of Spain. They presented the Renewable Energy development during the first years of plan management, and discussed the effect of additional issues. They used MCDM techniques, and also performed SWOT analysis to determine the problems and future plans. Loken (2007) presented a literature review about the implementation of MCDM instruments in energy planning problems. Mavrotas et al. (2008) modeled the uncertain power demand by using a multi-objective mathematical programming approach. They aimed at minimizing the total cost, and maximizing the demand satisfaction degree. Lee et al. (2008) focused on the energy conservation and alternative energy resources related to the needs of Korea, and they analyzed the hydrogen energy technology potential of Korea using AHP. Terrados et al. (2009) aimed at contributing to the development of renewable energies at a regional level, and proposed a methodology to create long-term strategies. By using SWOT analysis, the diagnosis was established. Then, the strategies were determined, and selected. 
They asked the opinions of experts related to these strategies using the Delphi technique, and by using MCDM, they ranked the alternatives and selected the strategies. Wang et al. (2009) analyzed the use of multiple-criteria decision-making (MCDM) methods related to energy planning in different stages such as criteria selection, criteria weighting, evaluation and conclusion summary. Tsoutsos et al. (2009) used MCDM methodology to determine the energy planning alternatives, and the alternatives were evaluated according to the economic, technical, social, and environmental criteria. Aragonés-Beltrán et al. (2010) used the ANP approach to select photovoltaic (PV) solar power projects for a Spanish company by minimizing the risk; thus, the best PV project was selected. Heo et al. (2010) studied the objective of new and renewable energy resources that would increase in Korea until 2030. The assessments of such decisions were made by using fuzzy AHP. Lee et al. (2011b) established a strategic energy technology roadmap for hydrogen energy technologies in the hydrogen economy, and applied the integrated two-stage MCDM approach, including the hybrid fuzzy AHP and data envelopment analysis (DEA) model to assess the relative efficiency of hydrogen energy technologies. Kaya and Kahraman (2011) suggested a modified fuzzy TOPSIS methodology to select the best energy alternative. The weights of the selection criteria were determined by fuzzy AHP. Cristóbal (2011) used the VIKOR method to select a renewable energy project corresponding to the renewable energy plan launched by the Spanish Government. Lee et al. (2011a) established a strategic hydrogen energy technology roadmap considering the economic impact, commercial potential, inner capacity, and technical spin-off and suggested a methodology to prioritize the relative weights of hydrogen energy technology roadmap (ETRM) by using a fuzzy AHP. Sueyoshi, Goto (2012) presented a combined application of data envelopment analysis (DEA) and DEADiscriminant Analysis (DA) to determine the efficiency-based rank of energy firms. By using DEA, the energy firms were classified, and then it utilized from DEA-DA to assess their efficiency scores and ranks. Xu and Chan (2013) aimed to use ANP to develop a model for sustainable Building Energy Efficiency Retrofit (BEER) under the energy performance contracting mechanism. Key performance indicators (KPIs) for sustainable BEER in hotel buildings and critical success factors (CSFs) for EPC were identified as being based upon a set of interview and questionnaire surveys that were previously conducted. Doukas et al. (2012) aimed to look deeply into the most appropriate renewable energy resources technology, which can be gradually introduced in the energy sector of Tajikistan, and supported their view through demonstrations, business workshops, guides for installers with technical details and design proposals. Streimikiene et al. (2013) aimed to look deeply into comparative assessment of energy technologies in road transport multi-criteria framework in order to develop and implement methods of MCDM for evaluating the transportation technologies. Balezentiene et al. (2013) presented a method based upon fuzzy MULTIMOOR which provides a framework of a multi-criteria decision making for prioritization of energy crops. Streimikiene and Balezentis (2013a) aimed to compare small-scale CHP technologies for buildings and ranked according to the criteria. Streimikiene and Balezentis (2013b) aimed to develop a technique for climate change mitigation assessment based upon the priorities of sustainable energy development. 
Unlike the aforementioned studies, a MCDM methodology consisting of AHP and TOPSIS based upon T2FS was proposed. In the proposed methodology, criteria for renewable energy sources in Turkey were weighted by IT2 Fuzzy AHP method. In the following step, the alternatives were ranked by using the IT2 Fuzzy TOPSIS method. After that, when ranking was analyzed, we determined the priority of which renewable energy alternatives must be used based upon Turkey's growing energy requirements in new economic order.

\section{Type-2 fuzzy sets}

In decision-making process, the information about the quality values is usually uncertain or fuzzy due to the increasing complexity of the socio-economic environment and the vagueness of inherent subjective nature of human thought. This fact has caused many authors to employ the fuzzy set (FS) theory to overcome the uncertainty and vagueness in decisionmaking processes (Wang et al. 2012; Wang, Elhag 2006).

Some fuzzy MCDM methods have been suggested as being based upon the type-1 fuzzy sets. T2FSs involve more uncertainties than type-1 fuzzy sets. They provide us additional degrees of freedom to represent the uncertainty and the fuzziness of the real-world. T2FSs can be regarded as an extension of type-1 fuzzy sets. T2FSs provide us a useful way to discuss fuzzy MCDM problems in a more flexible and more intelligent manner due to the fact that it uses interval type- 2 fuzzy sets rather than traditional type-1 fuzzy sets in order to represent the evaluation values and the weights of attributes (Lee, Chen 2008a, 2008c).

T2FSs, characterized by primary and secondary membership, are the extension of type-1 fuzzy sets ( $\mathrm{Hu}$ et al. 2013). In the literature, there have been some studies about T2FSs. Chen and Lee (2010a) presented an interval type-2 fuzzy technique for order preference similar to an ideal solution (TOPSIS) to discuss decision-making problems based upon TOPSIS. Vahdani and Hadipour (2011) proposed an ELECTRE method based on IT2FSs to overcome a problem involving the selection of a maintenance strategy. Chen (2011a) suggested a useful method for estimating the importance of the criteria in the MCDA and for reducing the leniency bias in decision-making processes based upon IT2FSs. Chen (2011b) benefited from several score functions based on interval type- 2 fuzzy point operators to quantify both optimistic and pessimistic estimations, and developed a model to reduce cognitive dissonance based upon IT2FSs. Chen (2012) proposed a MCDM method with generalized interval-valued fuzzy numbers under incomplete weight information. Wang et al. (2012) developed MCDM methods based upon the ranking values and the arithmetic operations of IT2FSs. Chen et al. (2012) also developed a method to address multiple attribute group decision-making problems based on ranking IT2FSs. Chen (2013b) presented a novel method for determining the objective importance of criteria and for handling multiple-criteria group decision-making problems based on IT2FSs.

The basic concepts and operations of T2FSs were introduced below, and we briefly analyzed some definitions of T2FS and IT2FSs. Blurring of the type-1 membership function (MF) depicted in Figure 1(a) by shifting the points on the triangle either to the left or 
to the right having no necessity to be at the same amounts was presented in Figure 1a(a), as in Figure 1(b). Then, at a specific value of $x, x^{y}$ expressed that there was no longer a single value for the MF; instead, the MF took on values wherever the vertical line intersects the blurring. Those values did not all need to be weighted as the same; hence, we could assign an amplitude distribution to all of those points. Doing this for all, we created a threedimensional MF-a T2 MF-that characterized a T2FS (Mendel et al. 2006).

Let $\tilde{A}$ be a type- 1 trapezoidal fuzzy set, $\tilde{A}=\left(a_{1}, a_{2}, a_{3}, a_{4} ; H_{1}(A), H_{2}(A)\right)$, as shown in Figure 2, where $H_{1}(\tilde{A})$ denoted the membership value of the element $a_{2} ; H_{2}(\tilde{A})$ denoted the membership value of the element $a_{3} ; 0 \leq H_{1}(A) \leq 1$ and $0 \leq H_{2}(A) \leq 1$. If $a_{2}=a_{3}$, then the type-2 fuzzy set $\tilde{A}$ became a triangular type-1 fuzzy set (Chen, Lee 2010b).

Definition 1. A type-2 fuzzy set $\tilde{\tilde{A}}$ in the universe of discourse $\mathrm{X}$ could be represented by a type-2 membership function, $\mu_{\tilde{\tilde{A}}}$, was shown as below (Zadeh 1975; Mendel, John 2002; Mendel et al. 2006; Chen, Lee 2010a):

$$
\tilde{\tilde{A}}=\left\{\left((x, u), \mu_{\tilde{\tilde{A}}}(x, u)\right) \mid \forall x \in X, \forall u \in J_{X} \subseteq[0,1], 0 \leq \mu_{\tilde{\tilde{A}}}(x, u) \leq 1\right\},
$$

$\underset{\tilde{\tilde{A}}}{\text { where }} 0 \leq \mu_{\tilde{\tilde{A}}}(x, u) \leq 1$ and $J_{X}$ denoted an interval in $[0,1]$. Moreover, the type- 2 fuzzy set $\tilde{\tilde{A}}$ also could be represented as below:

$$
\tilde{\tilde{A}}=\int_{x \in X} \int_{u \in J_{X}} \mu_{\tilde{\tilde{A}}}(x, u) /(x, u)=\int_{x \in X}\left[\int_{u \in \int_{x}} \mu_{\tilde{\tilde{A}}}(x, u) / u\right] / x,
$$

where $J_{X} \subseteq[0,1]$ and $\iint$ denoted union over all admissible $\mathrm{x}$ and $u$. $\mathrm{x}$ was the primary variable, $J_{X} \subseteq[0,1]$ was the primary membership of $x, u$ was the secondary variable, and $\int_{u \in \int_{x}} \mu_{\tilde{\tilde{A}}}(x, u) / u$ was the secondary membership function (MF) at $x . \iint$ denoted the union over all admissible $x$ and $u$. For discrete universes of discourse, $\int$ was replaced by $\sum$.

a)

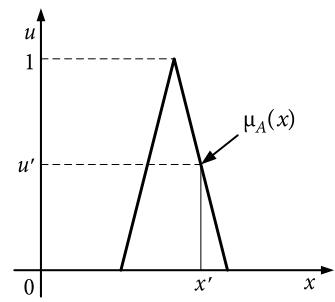

b)



Fig. 1. (a) Type-1 MF. (b) Blurred type-1 MF (Chen, Lee 2010)

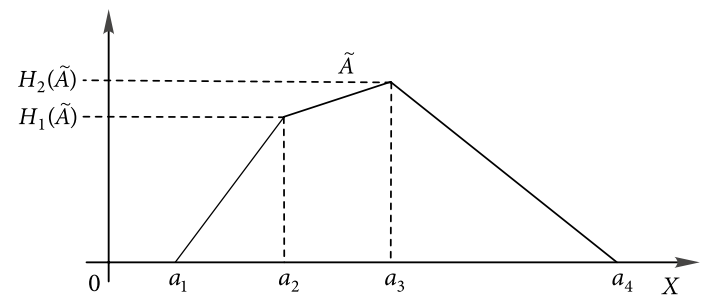

Fig. 2. A type-1 trapezoidal fuzzy set (Chen, Lee 2010) 
Definition 2. Let $\tilde{\tilde{A}}$ be a type-2 fuzzy set in the universe of discourse where $\mathrm{X}$ was represented by the type- 2 membership function $\mu_{\tilde{\tilde{A}}}$. If all $\mu_{\tilde{\tilde{A}}}(x, u)=1$, then $\tilde{\tilde{A}}$ was called an interval type- 2 fuzzy set. An interval type- 2 fuzzy set $\tilde{A}$ could be regarded as a special case of a type-2 fuzzy set, represented as below (Mendel et al. 2006; Wu, Mendel 2007a; Chen, Lee 2010a; Wang et al. 2012).

$$
\tilde{\tilde{A}}=\int_{x \in X} \int_{u \in J_{X}} 1 /(x, u)=\int_{x \in X}\left[\int_{u \in j_{x}} 1 / u\right] / x
$$

where $x$ was the primary variable, $J_{X} \subseteq[0,1]$ was the primary membership of $x, u$ was the secondary variable, and $\int_{u \in j_{x}} 1 / u$ was the secondary membership function (MF) at $x$.

Definition 3. In this paper, we presented a method to use IT2FS for handling fuzzy MCDM problems, where the reference points and the heights of the upper and the lower membership functions of IT2FS were used to characterize IT2FS. The upper membership function and the lower membership function of an interval type- 2 fuzzy set were type- 1 membership functions, respectively. It could be formulated as below:

$$
\tilde{\tilde{A}}_{i}=\left(\tilde{A}_{i}^{U}, \tilde{A}_{i}^{L}\right)=\left(\left(a_{i 1}^{U}, a_{i 2}^{U}, a_{i 3}^{U}, a_{i 4}^{U} ; H_{1}\left(\tilde{A}_{i}^{U}\right), H_{2}\left(\tilde{A}_{i}^{U}\right)\right),\left(a_{i 1}^{L}, a_{i 2}^{L}, a_{i 3}^{L}, a_{i 4}^{L} ; H_{1}\left(\tilde{A}_{i}^{L}\right), H_{2}\left(\tilde{A}_{i}^{L}\right)\right)\right),
$$

where $\tilde{A}_{i}^{U}$ and $\tilde{A}_{i}^{L}$ were type-1 fuzzy sets, $a_{i 1}^{U}, a_{i 2}^{U}, a_{i 3}^{U}, a_{i 4}^{U}, a_{i 1}^{L}, a_{i 2}^{L}, a_{i 3}^{L}$ and $a_{i 4}^{L}$ were the reference points of the interval type-2 fuzzy $\tilde{\tilde{A}}_{i} ; H_{j}\left(\tilde{A}_{i}^{U}\right)$ denoted the membership value of the element $a_{i(j+1)}^{U}$ in the upper trapezoidal membership function $\tilde{A}_{i}^{U} ; 1 \leq j \leq 2, H_{j}\left(\tilde{A}_{i}^{L}\right)$ denoted the membership value of the element $a_{i(j+1)}^{L}$ in the lower trapezoidal membership function $\tilde{A}_{i}^{L} ; 1 \leq j \leq 2, H_{j}\left(\tilde{A}_{i}^{L}\right)$ (Mendel et al. 2006; Chen, Lee 2010a; Wang et al. 2012; Celik et al. 2013).

Definition 4. The ranking value $\operatorname{Rank}\left(\tilde{\tilde{A}}_{i}\right)$ of the trapezoidal interval type-2 fuzzy set $\tilde{\tilde{A}}_{i}$ was defined as below (Lee, Chen 2008b; Chen, Lee 2010a; Chen et al. 2011):

$$
\begin{aligned}
& \operatorname{Rank}\left(\tilde{\tilde{A}}_{i}\right)=M_{1}\left(\tilde{A}_{i}^{U}\right)+M_{1}\left(\tilde{A}_{i}^{L}\right)+M_{2}\left(\tilde{A}_{i}^{U}\right)+M_{2}\left(\tilde{A}_{i}^{L}\right)+M_{3}\left(\tilde{A}_{i}^{U}\right)+M_{3}\left(\tilde{A}_{i}^{L}\right) \\
& -\frac{1}{4}\left(S_{1}\left(\tilde{A}_{i}^{U}\right)+S_{1}\left(\tilde{A}_{i}^{L}\right)+S_{2}\left(\tilde{A}_{i}^{U}\right)+S_{2}\left(\tilde{A}_{i}^{L}\right)+S_{3}\left(\tilde{A}_{i}^{U}\right)+S_{3}\left(\tilde{A}_{i}^{L}\right)+S_{4}\left(\tilde{A}_{i}^{U}\right)+S_{4}\left(\tilde{A}_{i}^{L}\right)\right), \\
& +H_{1}\left(\tilde{A}_{i}^{U}\right)+H_{1}\left(\tilde{A}_{i}^{L}\right)+H_{2}\left(\tilde{A}_{i}^{U}\right)+H_{2}\left(\tilde{A}_{i}^{L}\right)
\end{aligned}
$$

where $M_{p}\left(\tilde{\tilde{A}}_{i}^{j}\right)$ denoted the average of the elements, $a_{i p}^{j}$ and $a_{i(p+1)}^{j}$,

$M_{p}\left(\tilde{\tilde{A}}_{i}^{j}\right)=\left(a_{i p}^{j}+a_{i(p+1)}^{j}\right) / 2,1 \leq p \leq 3$, denoted the standard deviation of the elements $a_{i q}^{j}$ and $a_{i(q+1)}^{j}, S_{q}\left(\tilde{A}_{i}^{j}\right)=\sqrt{\frac{1}{2} \sum_{k=q}^{q+1}\left(a_{i k}^{j}-\frac{1}{2} \sum_{k=q}^{q+1} a_{i k}^{j}\right)^{2}}, 1 \leq q \leq 3, S_{4}\left(\tilde{A}_{i}^{j}\right)$ denoted the standard deviation of the elements $a_{i 1}^{j}, a_{i 2}^{j}, a_{i 3}^{j}, a_{i 4}^{j}, S_{4}\left(\tilde{A}_{i}^{j}\right)=\sqrt{\frac{1}{4} \sum_{k=1}^{4}\left(a_{i k}^{j}-\frac{1}{4} \sum_{k=1}^{4} a_{i k}^{j}\right)^{2}} H_{p}\left(\tilde{A}_{i}^{j}\right)$ denoted the membership value of the element $a_{i(p+1)}^{j}$ in the trapezoidal membership function $\tilde{A}_{i}^{j}, 1 \leq p \leq 3, j \in\{U, L\}$, and $1 \leq i \leq n$. Figure 3 showed a trapezoidal interval type-2 fuzzy set. 


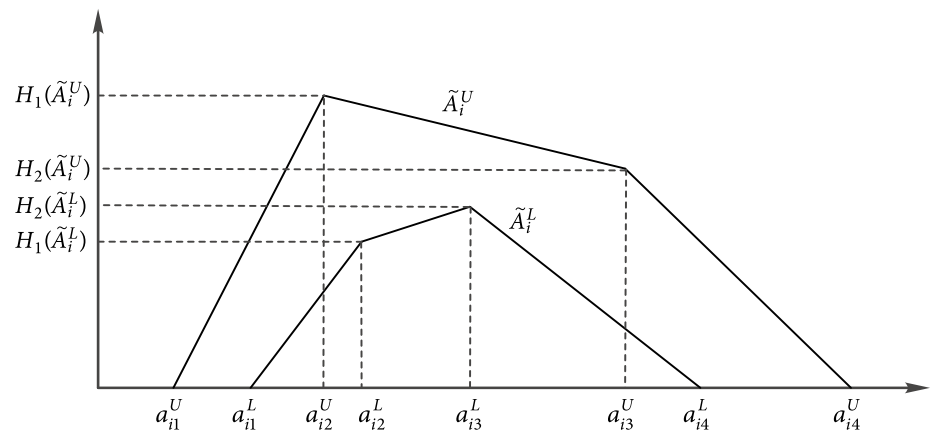

Fig. 3. Trapezoidal membership function of the interval type-2 fuzzy set $\tilde{\tilde{A}}$ (Lee, Chen 2008)

The upper trapezoidal membership function of $\tilde{A}_{i}^{U}$ and the lower trapezoidal membership function of $\tilde{A}_{i}^{L}$ were used for the interval type-2 fuzzy set in order to overcome fuzzy MCDM problems. Interval type-2 fuzzy sets were used to characterize $(\tilde{\tilde{A}})$ as below (Mendel et al. 2006; Lee, Chen 2008b; Chen, Lee 2010a; Wang et al. 2012). Let,

$\tilde{\tilde{A}}_{1}=\left(\tilde{A}_{1}^{U}, \tilde{A}_{1}^{L}\right)=\left(\left(a_{11}^{U}, a_{12}^{U}, a_{13}^{U}, a_{14}^{U} ; H_{1}\left(\tilde{A}_{1}^{U}\right), H_{2}\left(\tilde{A}_{1}^{U}\right)\right),\left(a_{11}^{L}, a_{12}^{L}, a_{13}^{L}, a_{14}^{L} ; H_{1}\left(\tilde{A}_{1}^{L}\right), H_{2}\left(\tilde{A}_{1}^{L}\right)\right)\right) ;$
$\tilde{\tilde{A}}_{2}=\left(\tilde{A}_{2}^{U}, \tilde{A}_{2}^{L}\right)=\left(\left(a_{21}^{U}, a_{22}^{U}, a_{23}^{U}, a_{24}^{U} ; H_{1}\left(\tilde{A}_{2}^{U}\right), H_{2}\left(\tilde{A}_{2}^{U}\right)\right),\left(a_{21}^{L}, a_{22}^{L}, a_{23}^{L}, a_{24}^{L} ; H_{1}\left(\tilde{A}_{2}^{L}\right), H_{2}\left(\tilde{A}_{2}^{L}\right)\right)\right)$.

\section{Addition:}

$\tilde{A}_{1} \oplus \tilde{A}_{2}=\left(\tilde{A}_{1}^{U}, \tilde{A}_{1}^{L}\right) \oplus\left(\tilde{A}_{2}^{U}, \tilde{A}_{2}^{L}\right)=$

$\left(\begin{array}{l}\left(a_{11}^{U}+a_{21}^{U}, a_{12}^{U}+a_{22}^{U}, a_{13}^{U}+a_{23}^{U}, a_{14}^{U}+a_{24}^{U} ; \min \left(H_{1}\left(\tilde{A}_{1}^{U}\right), H_{1}\left(\tilde{A}_{2}^{U}\right)\right), \min \left(H_{2}\left(\tilde{A}_{1}^{U}\right), H_{2}\left(\tilde{A}_{2}^{U}\right)\right)\right), \\ \left(a_{11}^{L}+a_{21}^{L}, a_{12}^{L}+a_{22}^{L}, a_{13}^{L}+a_{23}^{L}, a_{14}^{L}+a_{24}^{L} ; \min \left(H_{1}\left(\tilde{A}_{1}^{L}\right), H_{1}\left(\tilde{A}_{2}^{L}\right)\right), \min \left(H_{2}\left(\tilde{A}_{1}^{L}\right), H_{2}\left(\tilde{A}_{2}^{L}\right)\right)\right)\end{array}\right)$.

\section{Subtraction:}

$\tilde{A}_{1} \Theta \tilde{A}_{2}=\left(\tilde{A}_{1}^{U}, \tilde{A}_{1}^{L}\right) \Theta\left(\tilde{A}_{2}^{U}, \tilde{A}_{2}^{L}\right)=$

$\left(\begin{array}{l}\left(a_{11}^{U}-a_{21}^{U}, a_{12}^{U}-a_{22}^{U}, a_{13}^{U}-a_{23}^{U}, a_{14}^{U}-a_{24}^{U} ; \min \left(H_{1}\left(\tilde{A}_{1}^{U}\right), H_{1}\left(\tilde{A}_{2}^{U}\right)\right), \min \left(H_{2}\left(\tilde{A}_{1}^{U}\right), H_{2}\left(\tilde{A}_{2}^{U}\right)\right)\right), \\ \left(a_{11}^{L}-a_{21}^{L}, a_{12}^{L}-a_{22}^{L}, a_{13}^{L}-a_{23}^{L}, a_{14}^{L}-a_{24}^{L} ; \min \left(H_{1}\left(\tilde{A}_{1}^{L}\right), H_{1}\left(\tilde{A}_{2}^{L}\right)\right), \min \left(H_{2}\left(\tilde{A}_{1}^{L}\right), H_{2}\left(\tilde{A}_{2}^{L}\right)\right)\right)\end{array}\right)$.

\section{Multiplication:}

$\tilde{A}_{1} \otimes \tilde{A}_{2}=\left(\tilde{A}_{1}^{U}, \tilde{A}_{1}^{L}\right) \otimes\left(\tilde{A}_{2}^{U}, \tilde{A}_{2}^{L}\right)=$

$\left(\begin{array}{l}\left(a_{11}^{U} \times a_{21}^{U}, a_{12}^{U} \times a_{22}^{U}, a_{13}^{U} \times a_{23}^{U}, a_{14}^{U} \times a_{24}^{U} ; \min \left(H_{1}\left(\tilde{A}_{1}^{U}\right), H_{1}\left(\tilde{A}_{2}^{U}\right)\right), \min \left(H_{2}\left(\tilde{A}_{1}^{U}\right), H_{2}\left(\tilde{A}_{2}^{U}\right)\right)\right), \\ \left(a_{11}^{L} \times a_{21}^{L}, a_{12}^{L} \times a_{22}^{L}, a_{13}^{L} \times a_{23}^{L}, a_{14}^{L} \times a_{24}^{L} ; \min \left(H_{1}\left(\tilde{A}_{1}^{L}\right), H_{1}\left(\tilde{A}_{2}^{L}\right)\right), \min \left(H_{2}\left(\tilde{A}_{1}^{L}\right), H_{2}\left(\tilde{A}_{2}^{L}\right)\right)\right)\end{array}\right)$.

\section{Arithmetic operation:}

$$
k \tilde{\tilde{A}}_{1}=\left(\begin{array}{l}
\left(k \times a_{11}^{U}, k \times a_{12}^{U}, k \times a_{13}^{U}, k \times a_{14}^{U} ; H_{1}\left(\tilde{A}_{1}^{U}\right), H_{2}\left(\tilde{A}_{1}^{U}\right)\right) \\
\left(k \times a_{11}^{L}, k \times a_{12}^{L}, k \times a_{13}^{L}, k \times a_{14}^{L} ; H_{1}\left(\tilde{A}_{1}^{L}\right), H_{2}\left(\tilde{A}_{1}^{L}\right)\right)
\end{array}\right) ;
$$




$$
\frac{\tilde{\tilde{A}}_{1}}{k}=\left(\begin{array}{l}
\left(\frac{1}{k} \times a_{11}^{U}, \frac{1}{k} \times a_{12}^{U}, \frac{1}{k} \times a_{13}^{U}, \frac{1}{k} \times a_{14}^{U} ; H_{1}\left(\tilde{A}_{1}^{U}\right), H_{2}\left(\tilde{A}_{1}^{U}\right)\right), \\
\left(\frac{1}{k} \times a_{11}^{L}, \frac{1}{k} \times a_{12}^{L}, \frac{1}{k} \times a_{13}^{L}, \frac{1}{k} \times a_{14}^{L} ; H_{1}\left(\tilde{A}_{1}^{L}\right), H_{2}\left(\tilde{A}_{1}^{L}\right)\right)
\end{array}\right),
$$

where $\mathrm{k}>0$.

\section{Type-2 fuzzy AHP methodology}

The analytic hierarchy process (AHP) is a widespread decision-making analysis instrument for modeling unstructured problems in real life. Based upon the pair-by-pair comparison values for a set of objects; AHP is performed to elicit a corresponding priority vector that indicates preferences. Since it is difficult to map qualitative preferences to point estimates, a degree of uncertainty will be associated with some or all pairwise comparison values in an AHP problem. The problem of generating such a priority vector in the uncertain pair-topair comparison environment is called the fuzzy AHP problem. The first task of the fuzzy AHP method is to decide on the relative importance of each pair of factors in the same hierarchy (Chang 1996; Yu 2002).

In this paper, we extended the AHP method for discussing the fuzzy MCDM problems based on interval type-2 fuzzy sets to determine weight matrix of the criteria. The steps of Fuzzy AHP based upon IT2FSs are as below (Chen et al. 2012; Krohling, Campanharo 2011; Lee, Chen 2008b);

Step 1. Construct fuzzy pair wise comparison matrices among all the criteria in the hierarchical structure.

where

$$
\tilde{\tilde{M}}=\left(\begin{array}{cccc}
1 & \tilde{\tilde{a}}_{12} & \cdots & \tilde{\tilde{a}}_{1 n} \\
\tilde{\tilde{a}}_{21} & 1 & \cdots & \tilde{\tilde{a}}_{2 n} \\
\vdots & \vdots & \ddots & \vdots \\
\tilde{\tilde{a}}_{n 1} & \tilde{\tilde{a}}_{n 2} & \cdots & 1
\end{array}\right)=\left(\begin{array}{cccc}
1 & \tilde{\tilde{a}}_{12} & \cdots & \tilde{\tilde{a}}_{1 n} \\
1 / \tilde{\tilde{a}}_{12} & 1 & \cdots & \tilde{\tilde{a}}_{2 n} \\
\vdots & \vdots & \ddots & \vdots \\
1 / \tilde{\tilde{a}}_{1 n} & 1 / \tilde{\tilde{a}}_{2 n} & \cdots & 1
\end{array}\right),
$$

$$
1 / \tilde{\tilde{a}}_{i j}=\left(\left(\frac{1}{\tilde{\tilde{a}}_{i j 4}^{U}}, \frac{1}{\tilde{\tilde{a}}_{i j 3}^{U}}, \frac{1}{\tilde{\tilde{a}}_{i j 2}^{U}}, \frac{1}{\tilde{\tilde{a}}_{i j 1}^{U}} ; H_{1}\left(\tilde{\tilde{a}}_{i j}^{U}\right), H_{2}\left(\tilde{\tilde{a}}_{i j}^{U}\right)\right),\left(\frac{1}{\tilde{\tilde{a}}_{i j 4}^{L}}, \frac{1}{\tilde{\tilde{a}}_{i j 3}^{L}}, \frac{1}{\tilde{\tilde{a}}_{i j 2}^{L}}, \frac{1}{\tilde{\tilde{a}}_{i j 1}^{L}} ; H_{1}\left(\tilde{\tilde{a}}_{i j}^{L}\right), H_{2}\left(\tilde{\tilde{a}}_{i j}^{L}\right)\right)\right) \text {. }
$$

Step 2. Use geometric mean technique to define the fuzzy geometric mean as follows:

where

$$
\tilde{\tilde{r}}_{i}=\left(\tilde{\tilde{a}}_{i 1} \otimes \tilde{\tilde{a}}_{i 2} \otimes \cdots \otimes \tilde{\tilde{a}}_{i n}\right)^{1 / n}
$$

$\sqrt[n]{\tilde{\tilde{a}}_{i 1}}=\left(\left(\sqrt[n]{\tilde{\tilde{a}}_{i j 4}^{U}}, \sqrt[n]{\tilde{\tilde{a}}_{i j 3}^{U}}, \sqrt[n]{\tilde{\tilde{a}}_{i j 2}^{U}}, \sqrt[n]{\tilde{\tilde{a}}_{i j 1}^{U}} ; H_{1}\left(\tilde{\tilde{a}}_{i j}^{U}\right), H_{2}\left(\tilde{\tilde{a}}_{i j}^{U}\right)\right),\left(\sqrt[n]{\tilde{\tilde{a}}_{i j 4}^{L}}, \sqrt[n]{\tilde{\tilde{a}}_{i j 3}^{L}}, \sqrt[n]{\tilde{\tilde{a}}_{i j 2}^{L}}, \sqrt[n]{\tilde{\tilde{a}}_{i j 1}^{L}} ; H_{1}\left(\tilde{\tilde{a}}_{i j}^{L}\right), H_{2}\left(\tilde{\tilde{a}}_{i j}^{L}\right)\right)\right)$.

Step 3. Calculate the fuzzy weights of each criterion using:

$$
\tilde{\tilde{w}}_{i}=\tilde{\tilde{r}}_{i} \otimes\left(\tilde{\tilde{r}}_{1} \oplus \tilde{\tilde{r}}_{2} \oplus \cdots \oplus \tilde{\tilde{r}}_{n}\right)^{-1} .
$$




\section{Type-2 fuzzy TOPSIS methodology}

TOPSIS method is a technique for order of preference similar to ideal solution. TOPSIS method is a popular approach for MCDM, and has been widely used in the literature. A fuzzy TOPSIS method allows discussing the uncertainty, which is inherent in the decision making problem. In this paper, we also used the extended TOPSIS method for discussing the fuzzy MCDM problems based upon interval type-2 fuzzy sets.

The steps of the proposed method were as below (Chen, Lee 2010a):

Step 1. Creating the decision matrix $Y_{p}$ of the $\mathrm{p}^{\text {th }}$ decision-maker and creating the average decision matrix $\bar{Y}$, respectively, shown as below:

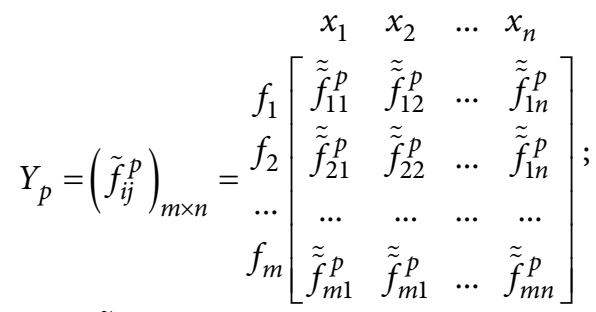

$$
\begin{aligned}
& \bar{Y}=\left(\tilde{\tilde{f}}_{i j}\right)_{m \times n},
\end{aligned}
$$

where $\tilde{\tilde{f}}_{i j}=\left(\frac{\tilde{\tilde{f}}_{i j}^{1} \oplus \tilde{\tilde{f}}_{i j}^{2} \oplus \ldots \oplus \tilde{\tilde{f}}_{i j}^{k}}{k}\right), \tilde{\tilde{f}}_{i j}$ was an interval type-2 fuzzy set,

$1 \leq i \leq m, 1 \leq j \leq n, 1 \leq p \leq k$ and $\mathrm{k}$ denoted the number of decision-makers.

Step 2. creating the weighting matrix $W_{p}$ of the attributes of the $\mathrm{p}^{\text {th }}$ decision-maker and creating the average weighting matrix $\bar{W}$, respectively, shown as below:

$$
\begin{aligned}
& \begin{array}{llll}
f_{1} & f_{2} & \ldots & f_{m}
\end{array} \\
& W_{p}=\left(\tilde{\tilde{w}}_{i}^{p}\right)_{1 \times m}=\left[\begin{array}{cccc}
\tilde{\tilde{w}}_{1}^{p} & \tilde{\tilde{w}}_{2}^{p} & \ldots & \tilde{\tilde{w}}_{m}^{p}
\end{array}\right] ; \\
& \bar{W}=\left(\tilde{\tilde{w}}_{i}\right)_{1 \times m},
\end{aligned}
$$

where $\tilde{\tilde{w}}_{i}=\left(\frac{\tilde{\tilde{w}}_{i}^{1} \oplus \tilde{\tilde{w}}_{i}^{2} \oplus \ldots \oplus \tilde{\tilde{w}}_{i}^{k}}{k}\right), \tilde{\tilde{w}}_{i}$ was an interval type-2 fuzzy set, $1 \leq i \leq m, 1 \leq p \leq k$ and $k$ denoted the number of decision makers.

In this paper, the weights of criteria were determined by using fuzzy AHP.

Step 3. Creating the weighted decision matrix $\bar{Y}_{w}$,

where $\tilde{\tilde{v}}_{i j}=\tilde{\tilde{w}}_{i} \otimes \tilde{\tilde{f}}_{i j}, 1 \leq i \leq m$ and $1 \leq j \leq n$.

$$
\bar{Y}_{w}=\left(\tilde{\tilde{v}}_{i j}\right)_{m \times n}=\begin{aligned}
& f_{1} \\
& f_{2} \\
& \ldots
\end{aligned}\left[\begin{array}{cccc}
\tilde{\tilde{v}}_{11} & \tilde{\tilde{v}}_{12} & \ldots & \tilde{\tilde{v}}_{1 n} \\
f_{m} & \tilde{\tilde{v}}_{22} & \ldots & \tilde{\tilde{v}}_{2 n} \\
\ldots & \ldots & \ldots & \ldots \\
\tilde{\tilde{v}}_{m 1} & \tilde{\tilde{v}}_{m 2} & \ldots & \tilde{\tilde{v}}_{m n}
\end{array}\right],
$$


Step 4. Based upon definition 4, calculating the ranking value $\tilde{\tilde{v}}_{i j}$ of the interval type-2 fuzzy set $\tilde{\tilde{v}}_{i j}$, where $1 \leq j \leq n$. Creating the ranking weighted decision matrix $\bar{Y}_{w}^{*}$,

$$
\bar{Y}_{w}^{*}=\left(\operatorname{Rank}\left(\tilde{\tilde{v}}_{i j}\right)\right)_{m \times n} ;
$$

where $1 \leq i \leq m$ and $1 \leq j \leq n$.

Step 5. Determining the positive ideal solution $x^{+}=\left(v_{1}^{+}, v_{2}^{+}, \ldots, v_{m}^{+}\right)$and the negative-ideal solution $x^{-}=\left(v_{1}^{-}, v_{2}^{-}, \ldots, v_{m}^{-}\right)$, where:

$$
\begin{gathered}
v_{i}^{+}= \begin{cases}\operatorname{Max}_{1 \leq j \leq n}\left\{\operatorname{Rank}\left(\tilde{\tilde{v}}_{i j}\right)\right\}, & \text { if } f_{i} \in F_{1}, \\
\operatorname{Min}_{1 \leq j \leq n}\left\{\operatorname{Rank}\left(\tilde{\tilde{v}}_{i j}\right)\right\}, & \text { if } f_{i} \in F_{2}\end{cases} \\
v_{i}^{-}=\left\{\begin{array}{ll}
\operatorname{Min}_{1 \leq j \leq n}\left\{\operatorname{Rank}\left(\tilde{\tilde{v}}_{i j}\right)\right\}, & \text { if } f_{i} \in F_{1} \\
\operatorname{Max}_{1 \leq j \leq n}\left\{\operatorname{Rank}\left(\tilde{\tilde{v}}_{i j}\right)\right\}, & \text { if } f_{i} \in F_{2}
\end{array},\right.
\end{gathered}
$$

where $F_{1}$ denoted the set of benefit attributes, $F_{2}$ denoted the set of cost attributes, and $1 \leq i \leq m$.

Step 6. Calculating the distance $d^{+}\left(x_{j}\right)$ between each alternative $x_{j}$ and the positive ideal solution $x^{+}$, was shown as below:

$$
d^{+}\left(x_{j}\right)=\sqrt{\sum_{i=1}^{m}\left(\operatorname{Rank}\left(\tilde{\tilde{v}}_{i j}\right)-v_{i}^{+}\right)^{2}},
$$

where $1 \leq j \leq n$. Calculating the distance $d^{-}\left(x_{j}\right)$ between each alternative $x_{j}$ and the negative-ideal solution $x^{-}$, was shown as below:

where $1 \leq j \leq n$.

$$
d^{-}\left(x_{j}\right)=\sqrt{\sum_{i=1}^{m}\left(\operatorname{Rank}\left(\tilde{\tilde{v}}_{i j}\right)-v_{i}^{-}\right)^{2}},
$$

Step 7. Calculating the relative degree of closeness $C C\left(x_{j}\right)$ of $x_{j}$ with respect to the positive ideal solution $x^{+}$, was shown as below:

$$
C C\left(x_{j}\right)=\frac{d^{-}\left(x_{j}\right)}{d^{+}\left(x_{j}\right)-d^{-}\left(x_{j}\right)},
$$

where $1 \leq j \leq n$.

Step 8. Sorting the values of $C C\left(x_{j}\right)$ in a descending sequence, where $1 \leq j \leq n$. The larger was the value of $C C\left(x_{j}\right)$, the higher was the preference of the alternative $x_{j}$, where $1 \leq j \leq n$.

In this paper, a fuzzy MCDM methodology based upon TOPSIS and AHP were extended with respect toT2FSs. The framework for the proposed fuzzy methodology was shown in Figure 4. 


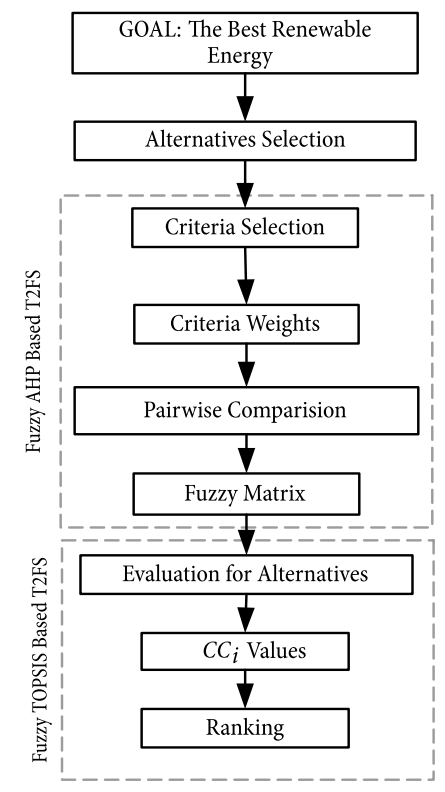

Fig. 4. The proposed fuzzy Type-2 Methodology

\section{A real case application for energy decision making in Turkey}

During the past 10-year period, Turkey has been the country that has the fastest increase in energy demand among the OECD countries. Turkey was the second largest economy with its rapidly increasing demand of energy (TMMOB 2012).

According to the Turkey Electricity Transmission Company (TEIAS) (2013), in 2012, Turkey's installed power capacity was increased from 53 thousand MW to 56.760 thousand MW. While 230 billion 306.3 million kilowatt-hours (kWh) of electricity was consumed in 2011, up to 241 billion 946.8 million $\mathrm{kWh}$ was reached with a 5.1 percent increase in 2012.

Turkey has the chance to meet their specific part energy needs from renewable energy sources. The energy alternatives considered are (Kreith, Goswami 2007):

- Geothermal energy (A1); the energy stored and created inside the earth in the form of thermal energy. Geothermal power plants produce steam using the underground hot water, and the energy is obtained through hitting of this steam to turbine.

- Solar energy (A2); Obtains energy from the sun by radiation. Solar energy is the energy provided by the sun directly to generate electricity, and is used to generate heat and light.

- Wind energy (A3); wind energy is obtained using special blades to catch the wind and convert it into electrical energy through machines.

- Hydraulic energy (A4); hydro-electric power plants convert the energy of the flowing water. This is primarily provided through dams built on rivers providing large-scale water to be reserved, and the water released out of dam turns the turbines in order to generate electricity. 
- Biomass energy (A5); biomass as a fuel is composed of organic matter like industrial waste, agricultural waste, wood, and bark.

- Hydrogen energy (A6); hydrogen can be produced from various sources, including fossil fuels, nuclear power, biomass, and renewable energy. This energy is a kind of energy produced by obtaining hydrogen from the renewable energy sources.

The structure of the renewable energy planning decision-making problem formulated in this study was presented in Figure 5.

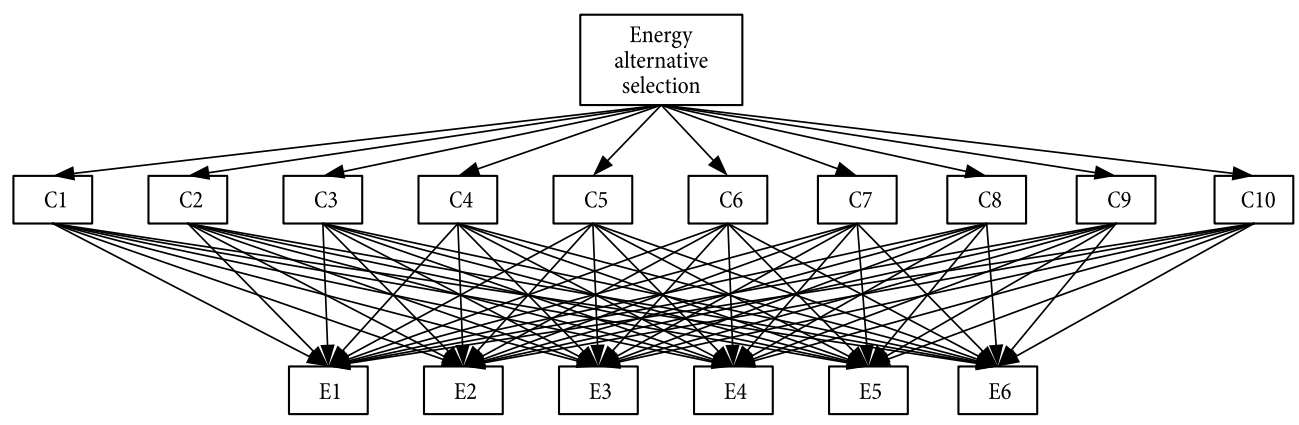

Fig. 5. The hierarchical structure for the selection of the renewable energy

The key dimensions of the criteria for evaluation and selection of renewable energy alternatives were derived through comprehensive investigation and consultation with three energy experts, including one associate professor in Department of Industrial Engineering, one expert in State Planning Organization (SPO), one expert in State Development Agency (SDA) in Turkey.

The criteria used in this study were as below (Wang et al. 2009):

- Efficiency (C1): Efficiency means the amount of beneficial energy that can be obtained from an energy resource. So, by means of the reliability and cheap raw-material of the big power plants, it depends upon its having steady development and its being economic and productive.

- Exergy efficiency (C2): Exergy efficiency measures the efficiency of a process according to the second law of thermodynamics. By including temperature variation, energy is wasted all the time.

- Investment cost (C3): Investment cost includes all costs related to buying of mechanical tools, installations of the technological equipment, building the roads, and connecting the networks to the national roads, engineering facilities, drilling and additional secondary process.

- Operation and maintenance cost (C4): Process and maintenance costs include two parts. One of them is cost of the process that includes wages of employees, and the other is the money given for the energy, the products and services for the operation of energy system.

- NOx emission (C5): $\mathrm{NOx}$ a general term for $\mathrm{NO}$ and $\mathrm{NO}_{2}$, has a direct effect upon the health of people and indirectly affects the social condition of the society. 
- $\mathrm{CO}_{2}$ emission (C6): Carbon dioxide which does not have a color, odor, and taste is a gas that is around 1.5 times denser than the air below regular conditions of pressure and temperature.

- Land use (C7): The environment and landscape are influenced straightly by the land which is full of energy systems. Additionally, land can be a common standard to assess the energy system.

- Social acceptability (C8): Social acceptability means determining the assumed perception of projects by the society revising the views of consumers. In other words, this term expresses the summary of local people's views upon the energy plants.

- Job creation (C9): Economic development and prosperity of the local people in regions where the power plants were established depends upon this power plant for decades. The long-standing power plants providing a more desirable life standards and employment for the local people are more convenient.

- Net Present Value (C10): NPV can be cleared as the whole current value of a time period of cash flows. NPV is a typical method which evaluates the worth of money depending on time in long standing energy studies.

After determining the evaluation criteria and the alternative set, the steps of the modified Type-2 fuzzy AHP algorithm was implemented for the decision matrix. In order to determine the relative importance of each evaluation criterion, the experts used a ninepoint scale which could be seen in Table 1 . Table 3 presented the comparison results of the evaluation criteria created by three energy planning experts.

Table 1. Fuzzy evaluation scores for the pairwise comparisons of criteria

\begin{tabular}{|c|c|c|c|c|c|c|c|c|c|c|}
\hline Lir & & & & & & & & & & \\
\hline bs & , 5.00, & U, & 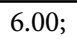 & .00 & 00), & .00 & 5.00 & . & 1.00 & \\
\hline Very Stı & $3.00,4.00$, & 4.00, & 5.00 & 1.00 & $.00),(3.50$ & 4.00, & 4.00 & 4.50 & 1.00 & 1.00 \\
\hline Fair Str & $((2.00,3.00$, & 3.00 & 4.00 & 1.00 & $1.00),(2.50$ & 3.00 & 3.00 & 4.50 & 1.00 & 1.00 \\
\hline Slightly & $((1.00,2.00$, & .00 & 300. & 1.00 & $1.00)$ & 2.00 & 2.00 & 3.50 & 1.00 & 800 \\
\hline Equal (E) & $((1.00,1.00$ & 1.00 & 1.00 & 1.00 & $1.00),(1.00$ & 1.00 & 1.00 & 1.00 & 1.00 & $1.00)$ \\
\hline Slowly We & $((0.33,0.50$, & 0.50 & 1.00 & 1.00 & 1.00), (0.29, & 0.50 & 0.50 & 0.67 & 1.00 & $1.00)$ \\
\hline Fair Week & $((0.25,0.33$, & 0.33 & 0.50 & 1.00 & $1.00),(0.22$ & 0.33 & 0.33 & 0.40 & 1.00 & 1.00 \\
\hline Very Week (VW) & $((0.20,0.25$, & 0.25 & 0.33 & 1.00 & $1.00),(0.2$ & $0 ?$ & 0.25 & 0.29 & 1.00 & $1.00)$ \\
\hline Absolutely Week (AW) & $(0.17,0.20$ & 0.20 & 0.25 & 1.00 & $1.00),(0.18$ & 0.20 & 0.20 & 0.22 & 1.00 & 1.00)) \\
\hline
\end{tabular}

Table 2. Fuzzy evaluation scores for the pairwise comparisons of alternatives

\begin{tabular}{lcccccccccccc}
\hline \multicolumn{1}{c}{ Linguistic terms } & \multicolumn{10}{c}{ Type-2 fuzzy sets } \\
\hline Very Low $(\mathrm{VL})$ & $((0.00$, & 0.00, & 0.00, & $0.10 ;$ & 1.00, & $1.00),(0.00$, & 0.00, & 0.00, & $0.05 ;$ & 0.90 & $0.90))$ \\
\hline Low $(\mathrm{L})$ & $((0.00$, & 0.10, & 0.10, & $0.30 ;$ & 1.00, & $1.00),(0.05$, & 0.10, & 0.10, & $0.20 ;$ & 0.90 & $0.90))$ \\
\hline Medium Low (ML) & $((0.10$, & 0.30, & 0.30, & $0.50 ;$ & 1.00, & $1.00),(0.20$, & 0.30, & 0.30, & $0.40 ;$ & 0.90 & $0.90))$ \\
\hline Medium (M) & $((0.30$, & 0.50, & 0.50, & $0.70 ;$ & 1.00, & $1.00),(0.40$, & 0.50, & 0.50, & $0.60 ;$ & 0.90 & $0.90))$ \\
\hline Medium High (MH) $)((0.50$, & 0.70, & 0.70, & $0.90 ;$ & 1.00, & $1.00),(0.60$, & 0.70, & 0.70, & $0.80 ;$ & 0.90 & $0.90))$ \\
\hline High (H) & $((0.70$, & 0.90, & 0.90, & $1.00 ;$ & 1.00, & $1.00),(0.80$, & 0.90, & 0.90, & $0.95 ;$ & 0.90 & $0.90))$ \\
\hline Very High $(\mathrm{VH})$ & $((0.90$, & 1.00, & 1.00, & $1.00 ;$ & 1.00, & $1.00),(0.95$, & 1.00, & 1.00, & $1.00 ;$ & 0.90 & $0.90))$ \\
\hline
\end{tabular}


Table 3. Linguistic expression for pairwise comparisons of evaluation criteria

\begin{tabular}{|c|c|c|c|c|c|c|c|c|c|c|c|}
\hline & & $\mathrm{C} 1$ & $\mathrm{C} 2$ & C3 & $\mathrm{C} 4$ & $\mathrm{C} 5$ & C6 & C7 & C8 & C9 & $\mathrm{C} 10$ \\
\hline \multirow{3}{*}{$\mathrm{C} 1$} & $D_{1}$ & 1 & FW & FW & FW & VW & AW & VW & SW & VW & $\mathrm{E}$ \\
\hline & $D_{2}$ & 1 & SW & SW & VW & VW & VW & FW & SW & VW & $\mathrm{E}$ \\
\hline & $D_{3}$ & 1 & SW & SW & VW & AW & AW & FW & SW & VW & E \\
\hline \multirow{3}{*}{$\mathrm{C} 2$} & $D_{1}$ & FS & 1 & $\mathrm{E}$ & SW & SW & FW & SW & SS & SW & FS \\
\hline & $D_{2}$ & SS & 1 & $\mathrm{E}$ & FW & FW & FW & SW & $\mathrm{E}$ & $\mathrm{FW}$ & FS \\
\hline & $D_{3}$ & SS & 1 & $\mathrm{E}$ & FW & VW & VW & SW & $\mathrm{E}$ & FW & SS \\
\hline \multirow{3}{*}{ C3 } & $D_{1}$ & FS & $\mathrm{E}$ & 1 & SW & SW & FW & SW & SS & SW & FS \\
\hline & $D_{2}$ & SS & $\mathrm{E}$ & 1 & FW & FW & FW & SW & $\mathrm{E}$ & FW & FS \\
\hline & $D_{3}$ & SS & $\mathrm{E}$ & 1 & FW & VW & VW & SW & $\mathrm{E}$ & FW & SS \\
\hline \multirow{3}{*}{$\mathrm{C} 4$} & $D_{1}$ & FS & SS & SS & 1 & E & SW & $\mathrm{E}$ & FS & $E$ & VS \\
\hline & $D_{2}$ & VS & FS & FS & 1 & $\mathrm{E}$ & E & SS & FS & FS & VS \\
\hline & $D_{3}$ & VS & FS & FS & 1 & SW & SW & SS & FS & $\mathrm{E}$ & VS \\
\hline \multirow{3}{*}{ C5 } & $D_{1}$ & VS & SS & SS & $\mathrm{E}$ & 1 & SW & $\mathrm{E}$ & $\mathrm{FS}$ & $\mathrm{E}$ & VS \\
\hline & $D_{2}$ & VS & FS & FS & $\mathrm{E}$ & 1 & $\mathrm{E}$ & SS & FS & FS & VS \\
\hline & $D_{3}$ & AS & VS & VS & SS & 1 & $\mathrm{E}$ & FS & VS & SS & AS \\
\hline \multirow{3}{*}{ C6 } & $D_{1}$ & AS & FS & FS & SS & SS & 1 & SS & VS & SS & AS \\
\hline & $D_{2}$ & VS & FS & FS & $\mathrm{E}$ & $\mathrm{E}$ & 1 & SS & FS & FS & VS \\
\hline & $D_{3}$ & AS & VS & VS & SS & $E$ & 1 & FS & VS & SS & AS \\
\hline \multirow{3}{*}{ C7 } & $D_{1}$ & VS & SS & SS & $\mathrm{E}$ & $\mathrm{E}$ & SW & 1 & FS & E & VS \\
\hline & $D_{2}$ & FS & SS & SS & SW & SW & SW & 1 & SS & SW & FW \\
\hline & $D_{3}$ & FS & SS & SS & SW & FW & FW & 1 & SS & SW & FS \\
\hline \multirow{3}{*}{ C8 } & $D_{1}$ & SS & SW & SW & FW & FW & VW & FW & 1 & VW & SS \\
\hline & $D_{2}$ & SS & $\mathrm{E}$ & $\mathrm{E}$ & FW & FW & FW & SW & 1 & FW & FS \\
\hline & $D_{3}$ & SS & $\mathrm{E}$ & $\mathrm{E}$ & FW & VW & VW & SW & 1 & $\mathrm{FW}$ & SS \\
\hline \multirow{3}{*}{ C9 } & $D_{1}$ & VS & SS & SS & $\mathrm{E}$ & E & SW & E & VS & 1 & VS \\
\hline & $D_{2}$ & VS & FS & FS & FW & FW & FW & SS & FS & 1 & VS \\
\hline & $D_{3}$ & VS & FS & FS & $\mathrm{E}$ & SW & SW & SS & FS & 1 & VS \\
\hline \multirow{3}{*}{$\mathrm{C} 10$} & $D_{1}$ & $\mathrm{E}$ & FW & FW & VW & VW & AW & VW & SW & VW & 1 \\
\hline & $D_{2}$ & $\mathrm{E}$ & FW & FW & VW & VW & VW & FS & FW & VW & 1 \\
\hline & $D_{3}$ & $\mathrm{E}$ & SW & SW & VW & AW & AW & $\mathrm{FW}$ & SW & VW & 1 \\
\hline
\end{tabular}

In the next step, using Tables 1 and 3, the fuzzy evaluation matrix for the criteria weights was obtained. In order to obtain this matrix, the geometric means of the fuzzy scores in Table 3 were calculated. In the next step, after obtaining the geometric means values, the weight vector was calculated. Finally, normalized weight vector was obtained as in Table 4.

AHP method requires determining whether there is any inconsistency with the comparison matrix of criteria. Because of that, it suggests the use of a consistency ratio. Consistency ratio, $\mathrm{CR}$, is acceptable when it is smaller than $10 \%$ value, and this means the matrix is consistent. Consistency analysis for this study, the CR value was obtained as (0.052). Therefore, the comparison matrix of criteria was acceptable and consistent results were obtained. 
Table 4. Results of the fuzzy AHP procedure for the determination of the weights

\begin{tabular}{|c|c|}
\hline & $\tilde{\tilde{W}}$ \\
\hline $\mathrm{C} 1$ & $(0.31,0.4,0.4,0.47 ; 0.9,0.9))$ \\
\hline $\mathrm{C} 2$ & $((0.57,0.77,0.77,1.09 ; 1,1),(0.58,0.77,0.77,0.97 ; 0.9,0.9))$ \\
\hline $\mathrm{C} 3$ & $((0.57,0.77,0.77,1.09 ; 1,1),(0.58,0.77,0.77,0.97 ; 0.9,0.9))$ \\
\hline $\mathrm{C} 4$ & $((1.38,1.86,1.86,2.38 ; 1,1),(1.59,1.86,1.86,2.4 ; 0.9,0.9))$ \\
\hline C5 & $((1.64,2.19,2.19,2.73 ; 1,1),(1.91,2.19,2.19,2.77 ; 0.9,0.9))$ \\
\hline C6 & $((1.79,2.53,2.53,3.22 ; 1,1),(2.17,2.53,2.53,3.34 ; 0.9,0.9))$ \\
\hline $\mathrm{C} 7$ & $((0.88,1.25,1.25,1.76 ; 1,1),(0.99,1.25,1.25,1.66 ; 0.9,0.9))$ \\
\hline $\mathrm{C} 8$ & $((0.49,0.64,0.64,0.89 ; 1,1),(0.5,0.64,0.64,0.8 ; 0.9,0.9))$ \\
\hline C9 & $((1.22,1.63,1.63,2.13 ; 1,1),(1.36,1.63,1.63,2.06 ; 0.9,0.9))$ \\
\hline $\mathrm{C} 10$ & $((0.35,0.44,0.44,0.6 ; 1,1), \quad(0.35,0.44,0.44,0.51 ; 0.9,0.9))$ \\
\hline
\end{tabular}

Next step is the determination of the best energy alternative with extends the TOPSIS method for handling fuzzy MCDM problems based upon IT2Fs procedure. Table 5 presented the results of the linguistic expression pairwise comparisons of the alternatives-criteria matrix made by energy planning experts. To do this, experts evaluated the energy alternatives in terms of each criterion using Table 2. While the experts evaluate the alternatives, they assumed that all the criteria were beneficial criteria.

Table 5. Linguistic expression for Evaluation scores of the alternatives

\begin{tabular}{|c|c|c|c|c|c|c|c|c|c|c|c|}
\hline & & $\mathrm{C} 1$ & $\mathrm{C} 2$ & $\mathrm{C} 3$ & $\mathrm{C} 4$ & $\mathrm{C} 5$ & C6 & C7 & C8 & C9 & $\mathrm{C} 10$ \\
\hline & $D_{1}$ & $\mathrm{H}$ & $\mathrm{M}$ & $\mathrm{M}$ & $\mathrm{M}$ & ML & $\mathrm{M}$ & $\mathrm{H}$ & $\mathrm{M}$ & $\mathrm{M}$ & $\mathrm{H}$ \\
\hline \multirow[t]{3}{*}{$\mathrm{A} 1$} & $D_{2}$ & $\mathrm{MH}$ & $\mathrm{M}$ & $\mathrm{MH}$ & $\mathrm{MH}$ & $\mathrm{M}$ & $\mathrm{M}$ & $\mathrm{MH}$ & $\mathrm{MH}$ & $\mathrm{MH}$ & $\mathrm{H}$ \\
\hline & $D_{3}$ & $\mathrm{H}$ & $\mathrm{MH}$ & $\mathrm{MH}$ & $\mathrm{M}$ & $\mathrm{M}$ & $\mathrm{ML}$ & $\mathrm{H}$ & $\mathrm{H}$ & $\mathrm{H}$ & $\mathrm{MH}$ \\
\hline & $D_{1}$ & $\mathrm{MH}$ & $\mathrm{VH}$ & $\mathrm{H}$ & $\mathrm{MH}$ & $\mathrm{VH}$ & $\mathrm{H}$ & $\mathrm{MH}$ & $\mathrm{MH}$ & ML & $\mathrm{ML}$ \\
\hline \multirow[t]{3}{*}{$\mathrm{A} 2$} & $D_{2}$ & $M$ & $\mathrm{MH}$ & $\mathrm{MH}$ & $M$ & $\mathrm{M}$ & $\mathrm{H}$ & $\mathrm{MH}$ & $\mathrm{MH}$ & $\mathrm{M}$ & $\mathrm{ML}$ \\
\hline & $D_{3}$ & $\mathrm{M}$ & $\mathrm{MH}$ & $\mathrm{H}$ & $\mathrm{H}$ & $\mathrm{M}$ & $\mathrm{MH}$ & $\mathrm{H}$ & $\mathrm{VH}$ & $\mathrm{VH}$ & $\mathrm{L}$ \\
\hline & $D_{1}$ & $\mathrm{H}$ & $\mathrm{L}$ & $\mathrm{H}$ & $\mathrm{H}$ & M & $\mathrm{H}$ & $\mathrm{H}$ & $\mathrm{H}$ & $\mathrm{H}$ & $\mathrm{H}$ \\
\hline \multirow[t]{3}{*}{ A3 } & $D_{2}$ & $\mathrm{MH}$ & ML & $\mathrm{H}$ & $M$ & $\mathrm{H}$ & $\mathrm{VH}$ & $\mathrm{VH}$ & $\mathrm{H}$ & $\mathrm{H}$ & $\mathrm{H}$ \\
\hline & $D_{3}$ & $\mathrm{H}$ & $\mathrm{MH}$ & $\mathrm{MH}$ & $\mathrm{MH}$ & $\mathrm{H}$ & $\mathrm{H}$ & $\mathrm{VH}$ & $\mathrm{H}$ & $\mathrm{H}$ & $\mathrm{H}$ \\
\hline & $D_{1}$ & $M$ & $\mathrm{MH}$ & $\mathrm{VL}$ & $\mathrm{VH}$ & $\mathrm{H}$ & $M$ & $\mathrm{H}$ & $\mathrm{L}$ & $\mathrm{L}$ & $\mathrm{VL}$ \\
\hline \multirow[t]{3}{*}{ A4 } & $D_{2}$ & $M$ & $\mathrm{H}$ & $\mathrm{VL}$ & $\mathrm{VL}$ & $M$ & $\mathrm{H}$ & $\mathrm{H}$ & $\mathrm{L}$ & $\mathrm{VL}$ & $\mathrm{VL}$ \\
\hline & $D_{3}$ & M & $\mathrm{MH}$ & $\mathrm{VH}$ & $\mathrm{VH}$ & $\mathrm{H}$ & $\mathrm{H}$ & ML & $\mathrm{VH}$ & $\mathrm{H}$ & VL \\
\hline & $D_{1}$ & $\mathrm{MH}$ & $\mathrm{H}$ & $\mathrm{H}$ & $\mathrm{H}$ & ML & M & M & M & $\mathrm{MH}$ & $\mathrm{VH}$ \\
\hline \multirow[t]{3}{*}{ A5 } & $D_{2}$ & $\mathrm{H}$ & $\mathrm{MH}$ & $M$ & $\mathrm{MH}$ & $M$ & $M$ & $\mathrm{M}$ & $\mathrm{MH}$ & $\mathrm{H}$ & $\mathrm{VH}$ \\
\hline & $D_{3}$ & $\mathrm{MH}$ & $\mathrm{MH}$ & $\mathrm{MH}$ & ML & M & ML & M & $\mathrm{MH}$ & $\mathrm{H}$ & $\mathrm{H}$ \\
\hline & $D_{1}$ & $\mathrm{VH}$ & $\mathrm{H}$ & $\mathrm{L}$ & ML & $\mathrm{VL}$ & $\mathrm{VL}$ & $\mathrm{L}$ & $\mathrm{VH}$ & $\mathrm{M}$ & $\mathrm{L}$ \\
\hline \multirow[t]{2}{*}{ A6 } & $D_{2}$ & $\mathrm{H}$ & $\mathrm{VH}$ & $\mathrm{L}$ & $\mathrm{ML}$ & $\mathrm{VL}$ & $\mathrm{VL}$ & $\mathrm{L}$ & $\mathrm{VH}$ & $\mathrm{M}$ & $\mathrm{L}$ \\
\hline & $D_{3}$ & $\mathrm{VH}$ & $\mathrm{H}$ & $\mathrm{ML}$ & $M$ & $\mathrm{VL}$ & $\mathrm{VL}$ & $\mathrm{L}$ & $\mathrm{VH}$ & $\mathrm{M}$ & $\mathrm{VL}$ \\
\hline
\end{tabular}




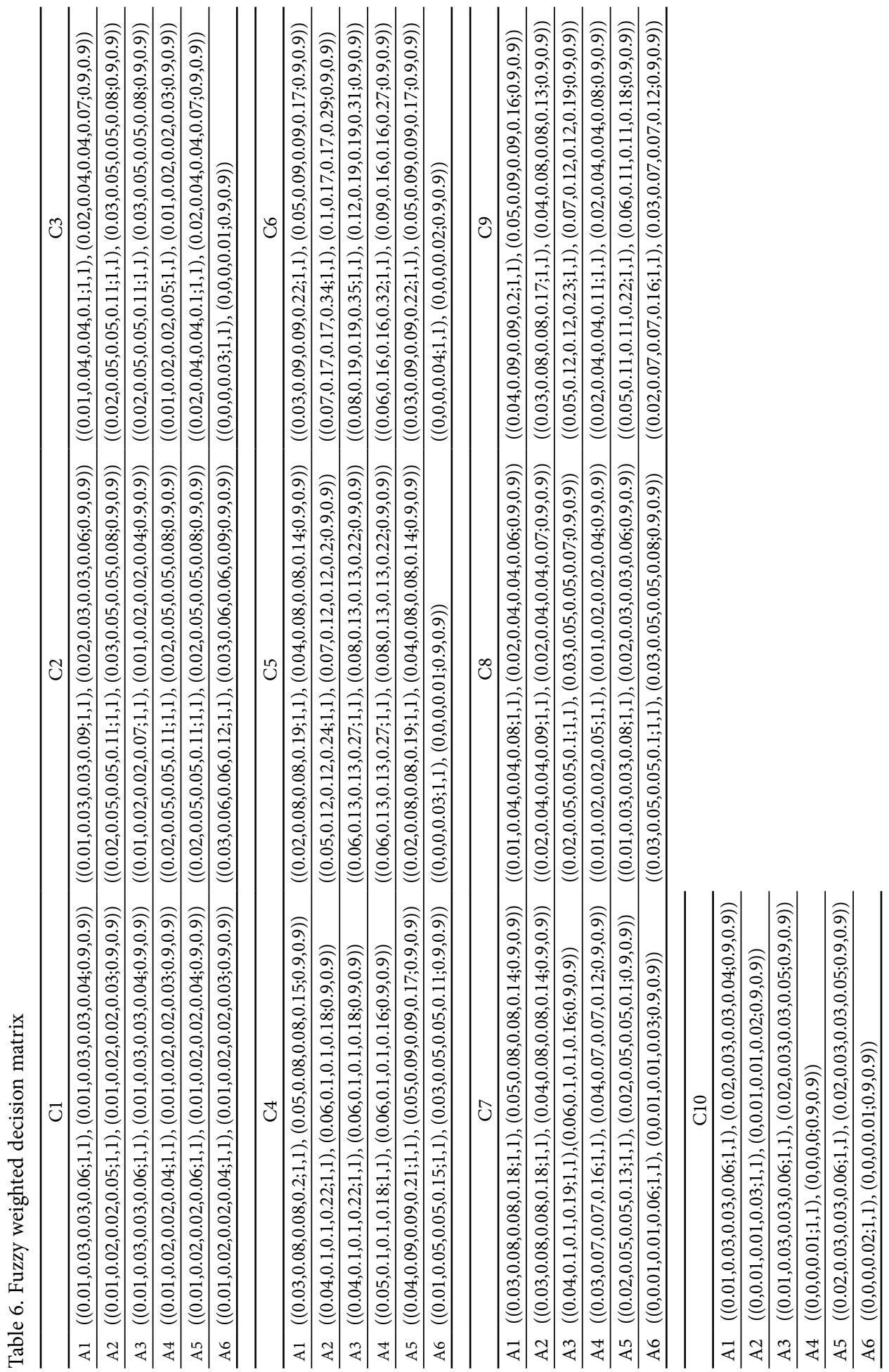


In the next step, calculating the arithmetic means of the associated fuzzy scores of the evaluation results were calculated by the experts, and the evaluation matrix was obtained. Following this step, the weighted normalized Type-2 fuzzy decision matrix was established as shown in Table 6. After obtaining the fuzzy weighted decision table, the positive ideal $\left(\right.$ FPIS,$\left.d_{i}^{+}\right)$solutions and negative ideal (FNIS, $d_{i}^{-}$) solutions were obtained as shown in Table 7. Finally, the closeness coefficient $\left(C C_{i}\right)$ of each alternative was calculated.

Table 7. The obtained results

\begin{tabular}{ccccc}
\hline & $d_{i}^{+}$ & $d_{i}^{-}$ & $C C_{i}$ & Rank \\
\hline $\mathrm{A} 1$ & 1.5465 & 2.3807 & 0.6062 & 5 \\
\hline $\mathrm{A} 2$ & 0.8396 & 3.0876 & 0.7862 & 2 \\
\hline $\mathrm{A} 3$ & 0.2391 & 3.6881 & 0.9391 & 1 \\
\hline $\mathrm{A} 4$ & 1.4525 & 2.4747 & 0.6301 & 3 \\
\hline $\mathrm{A} 5$ & 1.4954 & 2.4318 & 0.6192 & 4 \\
\hline $\mathrm{A} 6$ & 3.4175 & 0.5097 & 0.1298 & 6 \\
\hline
\end{tabular}

According to Table 7, the ranking of the alternatives was A3-A2-A4-A5-A1, and A6. The best alternative was determined as wind energy. The order of the rest was as solar, hydraulic, biomass, geothermal, and hydrogen energy.

\section{Conclusions}

The development and use of renewable energy sources and technologies have increasingly been becoming crucial for sustainable economic development of a country. For that reason, renewable energy is reliable and abundant, and will potentially be very cheap once technology and infrastructure has been improved and managed to meet the energy demand.

In this paper, we used both interval type-2 fuzzy TOPSIS method and interval type-2 fuzzy AHP method together to discuss the fuzzy MCDM problems for energy planning and investment. These methods provide us a useful way to deal with the fuzzy MCDM problems. They are more intelligent, flexible, and sensitive than the traditional type- 1 fuzzy sets. Interval type-2 fuzzy number has more flexibility in capturing uncertainties in the real world due to the fact that it is defined by primary and secondary membership.

In this paper, we proposed a new fuzzy MCDM method based upon T2FSs. In the first stage, the criteria weights were determined by interval type- 2 fuzzy AHP method. Then, all the alternatives were calculated according to the ranking vector determined by interval type- 2 fuzzy TOPSIS method. The proposed methodology was used to determine the best suitable renewable energy alternative for Turkey. The best alternative was determined as wind energy, the rest were as solar, hydraulic, biomass, geothermal, and hydrogen energy, respectively. This result was the outcome of a survey carried out by three energy planning experts who ranked the energy alternatives according to ten criteria that we selected. If possible, increasing the number of experts in the survey would help support the claims. 
In the future, we can perform the proposed methodology to other decision-making problems such as selection of supplier, selection of facility location, selection of material, and selection of software.

\section{References}

Abulfotuh, F. 2007. Energy efficiency and renewable technologies: the way to sustainable energy future, Desalination 209: 275-282. http://dx.doi.org/10.1016/j.desal.2007.04.040

Aisbett, J.; Rickard, J. T.; Morgenthaler, D. 2011. Multivariate modeling and type-2 fuzzy sets, Fuzzy Sets and Systems 163: 78-95. http://dx.doi.org/10.1016/j.fss.2010.10.001

Aragonés-Beltrán, P.; Chaparro-González, F.; Pastor-Ferrando, J. P.; Rodríguez-Pozo, F. 2010. An ANP based approach for the selection of photovoltaic solar power plant investment projects, Renewable and Sustainable Energy Reviews 14: 249-264. http://dx.doi.org/10.1016/j.rser.2009.07.012

Balezentiene, L.; Streimikiene, D.; Balezentis, T. 2013. Fuzzy decision support methodology for sustainable energy crop selection, Renewable and Sustainable Energy Reviews 17: 83-93. http://dx.doi.org/10.1016/j.rser.2012.09.016

Celik, E.; Bilisik, O. N.; Erdogan, M.; Gumus, A. T.; Baracli, H. 2013. An integrated novel interval type2 fuzzy MCDM method to improve customer satisfaction in public transportation for Istanbul, Transportation Research Part E: Logistics and Transportation Review 58: 28-51. http://dx.doi.org/10.1016/j.tre.2013.06.006

Chang, D. Y. 1996. Applications of the extent analysis method on fuzzy AHP, European Journal of Operational Research 95: 649-655. http://dx.doi.org/10.1016/0377-2217(95)00300-2

Chang, N. B.; Parvathinathan, G.; Breeden, J. B. 2008. Combining GIS with fuzzy multicriteria decisionmaking for landfill siting in a fast-growing urban region, Journal of Environmental Management 87: 139-153. http://dx.doi.org/10.1016/j.jenvman.2007.01.011

Chen, S. M.; Lee, L. W. 2010a. Fuzzy multiple attributes group decision-making based on the interval type-2 TOPSIS method, Expert Systems with Applications 37(4): 2790-2798.

http://dx.doi.org/10.1016/j.eswa.2009.09.012

Chen, S. M.; Lee, L. W. 2010b. Fuzzy multiple attributes group decision-making based on the ranking values and the arithmetic operations of interval type-2 fuzzy sets, Expert Systems with Applications 37: 824-833. http://dx.doi.org/10.1016/j.eswa.2009.06.094

Chen, S. M.; Yang, M. W.; Lee, L. W. 2011. A new method for fuzzy multiple attributes group decision making based on ranking interval type-2 fuzzy sets, in Proceedings of the 2011 International Conference on Machine Learning And Cybernetics, 10-13 July 2011, Guilin, China, 10-13.

http://dx.doi.org/10.1109/icmlc.2011.6016692

Chen, S. M.; Yang, M. W.; Lee, L. W.; Yang, S. W. 2012. Fuzzy multiple attributes group decision-making based on ranking interval type-2 fuzzy sets, Expert Systems with Applications 39(5): 5295-5308. http://dx.doi.org/10.1016/j.eswa.2011.11.008

Chen, T. Y. 2011a. Multi-criteria decision-making method with leniency reduction based on intervalvalued fuzzy sets, Journal of the Chinese Institute of Industrial Engineers 28(1): 1-19. http://dx.doi.org/10.1080/10170669.2010.528919

Chen, T. Y. 2011b. Optimistic and pessimistic decision making with dissonance reduction using intervalvalued fuzzy sets, Information Sciences 181(3): 479-502. http://dx.doi.org/10.1016/j.ins.2010.10.005

Chen, T. Y. 2012. Multiple criteria group decision-making with generalized interval-valued fuzzy numbers based on signed distances and incomplete weights, Applied Mathematical Modelling 36(7): 3029-3052. http://dx.doi.org/10.1016/j.apm.2011.09.080 
Chen, T. Y. 2013a. A linear assignment method for multiple-criteria decision analysis with interval type2 fuzzy sets, Applied Soft Computing 13: 2735-2748. http://dx.doi.org/10.1016/j.asoc.2012.11.013

Chen, T. Y. 2013b. A signed-distance-based approach to importance assessment and multi-criteria group decision analysis based on interval type-2 fuzzy set, Knowledge and Information Systems 35: 193-231. http://dx.doi.org/10.1007/s10115-012-0497-6

Cristóbal, J. R. S. 2011. Multi-criteria decision-making in the selection of a renewable energy project in Spain: The Vikor method, Renew Energy 36: 498-502. http://dx.doi.org/10.1016/j.renene.2010.07.031

Demirbas, A. 2008. Importance of biomass energy sources for Turkey, Energy Policy 36: 834-842. http://dx.doi.org/10.1016/j.enpol.2007.11.005

Doukas, H.; Marinakis, V.; Karakosta, C.; Psarras, J. 2012. Promoting renewable in the energy sector of Tajikistan, Renew Energy 39: 411-418. http://dx.doi.org/10.1016/j.renene.2011.09.007

Erdogmus, S.; Aras, H.; Koc, E. 2006. Evaluation of alternative fuels for residential heating in Turkey using analytic network process (ANP) with group decision-making, Renewable and Sustainable Energy Reviews 10: 269-279. http://dx.doi.org/10.1016/j.rser.2004.09.003

Heo, E.; Kim, J.; Boo, K. 2010. Analysis of the assessment factors for renewable energy dissemination program evaluation using fuzzy AHP, Renewable and Sustainable Energy Reviews 14: 2214-2220. http://dx.doi.org/10.1016/j.rser.2010.01.020

Hu, J.; Zhang, Y.; Chen, X.; Liu, Y. 2013. Multi-criteria decision making method based on possibility degree of interval type-2 fuzzy number, Knowledge-Based Systems 43: 21-29.

http://dx.doi.org/10.1016/j.knosys.2012.11.007

Kahraman, C.; Kaya, I.; Cebi, S. 2009. A comparative analysis for multiattribute selection among renewable energy alternatives using fuzzy axiomatic design and fuzzy analytic hierarchy process, Energy 34: 1603-1616. http://dx.doi.org/10.1016/j.energy.2009.07.008

Kaya, T.; Kahraman, C. 2010. Multicriteria renewable energy planning using an integrated fuzzy VIKOR \& AHP methodology: the case of Istanbul, Energy 35 (6): 2517-2527. http://dx.doi.org/10.1016/j.energy.2010.02.051

Kaya, T.; Kahraman, C. 2011. Multi criteria decision making in energy planning using a modified fuzzy TOPSIS methodology, Expert Systems with Applications 38: 6577-6585.

http://dx.doi.org/10.1016/j.eswa.2010.11.081

Kaygusuz, K. 2002. Environmental impacts of energy utilisation and renewable energy policies in Turkey, Energy Policy 30: 689-698. http://dx.doi.org/10.1016/S0301-4215(02)00032-0

Kreith, F.; Goswami, D. Y. (Eds.) 2007. Handbook of energy efficiency and renewable energy. Crc Press. http://dx.doi.org/10.1201/9781420003482

Krohling, R. A.; Campanharo, V. C. 2011. Fuzzy TOPSIS for group decision making: a case study for accidents with oil spill in the sea, Expert Systems with Applications 38(4): 4190-4197. http://dx.doi.org/10.1016/j.eswa.2010.09.081

Lee, L. W.; Chen, S. M. 2008a. Fuzzy multiple attributes hierarchical group decision-making based on the ranking values of interval type-2 fuzzy sets, Proceedings of the Seventh International Conference on Machine Learning and Cybernetics, 12-15 July 2008, Kunming, 69: 3260-3265.

http://dx.doi.org/10.1109/ICMLC.2008.4620969

Lee, L. W.; Chen, S. M. 2008b. A new method for fuzzy multiple attributes group decision-making based on the arithmetic operations of interval type-2 fuzzy sets, Proceedings of the Seventh International Conference on Machine Learning and Cybernetics (6): 3084-3089.

http://dx.doi.org/10.1109/ICMLC.2008.4620938

Lee, L. W.; Chen, S. M. 2008c. Fuzzy multiple attributes group decision-making based on the extension of TOPSIS method and interval type-2 fuzzy sets, in Proceedings of 2008 International Conference on Machine Learning and Cybernetics, 12-15 July 2008, Kunming, 3260-3265.

http://dx.doi.org/10.1109/ICMLC.2008.4620968 
Lee, S. K.; Mogi, G.; Kim, J. W. 2008. The competitiveness of Korea as a developer of hydrogen energy technology: the AHP approach, Energy Policy 36: 1284-1291.

http://dx.doi.org/10.1016/j.enpol.2007.12.003

Lee, S. K.; Mogi, G.; Lee, S. K.; Kim, J. W. 2011a. Prioritizing the weights of hydrogen energy technologies in the sector of the hydrogen economy by using a fuzzy AHP approach, International Journal of Hydrogen Energy 36: 1897-1902. http://dx.doi.org/10.1016/j.ijhydene.2010.01.035

Lee, S. K.; Mogi, G.; Li, Z.; Hui, K. S.; Lee, S. K.; Hui, K. N.; Park, S. Y.; Ha, Y. J.; Kim, J. W. 2011 b. Measuring the relative efficiency of hydrogen energy technologies for implementing the hydrogen economy: an integrated fuzzy AHP/DEA approach, International Journal of Hydrogen Energy 36: 12655-12663. http://dx.doi.org/10.1016/j.ijhydene.2011.06.135

Loken, E. 2007. Use of multicriteria decision analysis methods for energy planning problems, Renewable and Sustainable Energy Reviews 11: 1584-1595. http://dx.doi.org/10.1016/j.rser.2005.11.005

Mavrotas, G.; Diakoulaki, D.; Florios, K.; Georgiou, P. 2008. A mathematical programming framework for energy planning in services' sector buildings under uncertainty in load demand: the case of a hospital in Athens, Energy Policy 36: 2415-2429. http://dx.doi.org/10.1016/j.enpol.2008.01.011

Mendel, J. M.; John, R. I.; Liu, F. L. 2006. Interval type-2 fuzzy logical systems made simple, IEEE Transactions on Fuzzy Systems 14(6): 808-821. http://dx.doi.org/10.1109/TFUZZ.2006.879986

Mendel, J. M.; John, R. I. B. 2002. Type-2 fuzzy sets made simple, IEEE Transactions on Fuzzy Systems 10(2): 117-127. http://dx.doi.org/10.1109/91.995115

Pohekar, S. D.; Ramachandran, M. 2004. Application of multi-criteria decision making to sustainable energy planning e a review, Renewable and Sustainable Energy Reviews 8: 365-381. http://dx.doi.org/10.1016/j.rser.2003.12.007

Samouilidis, J.; Mitropoulos, C. 1982. Energy economy models: a survey, European Journal of Operational Research 11(3): 222-232. http://dx.doi.org/10.1016/0377-2217(82)90246-6

Soytas, U.; Sari, R. 2006. Energy consumption and income in G-7 countries, Journal of Policy Modeling 28: 739-750. http://dx.doi.org/10.1016/j.jpolmod.2006.02.003

Streimikiene, D.; Baležentis, T. 2013a. Multi-criteria assessment of small scale CHP technologies in buildings, Renewable and Sustainable Energy Reviews 26: 183-189.

http://dx.doi.org/10.1016/j.rser.2013.05.046

Streimikiene, D.; Balezentis, T. 2013b. Multi-objective ranking of climate change mitigation policies and measures in Lithuania, Renewable and Sustainable Energy Reviews 18: 144-153. http://dx.doi.org/10.1016/j.rser.2012.09.040

Streimikiene, D.; Baležentis, T.; Baležentienè, L. 2013. Comparative assessment of road transport technologies, Renewable and Sustainable Energy Reviews 20: 611-618. http://dx.doi.org/10.1016/j.rser.2012.12.021

Sueyoshi, T.; Goto, M. 2012. Efficiency-based rank assessment for electric power industry: a combined use of Data Envelopment Analysis (DEA) and DEA-Discriminate Analysis (DA), Energy Economics 34: 634-644. http://dx.doi.org/10.1016/j.eneco.2011.04.001

Terrados, J.; Almonacid, G.; Hontoria, L. 2007. Regional energy planning through SWOT analysis and strategic planning tools. Impact on renewable development, Renewable and Sustainable Energy Reviews 11: 1275-1287. http://dx.doi.org/10.1016/j.rser.2005.08.003

Terrados, J.; Almonacid, G.; Perez-Higueras, P. 2009. Proposal for a combined methodology for renewable energy planning. Application to a Spanish region, Renewable and Sustainable Energy Reviews 13: 2022-2030. http://dx.doi.org/10.1016/j.rser.2009.01.025

TMMOB. 2012. Turkey's Energy Outlook. 2nd ed. Union of Chambers of Turkish Engineers and Architects. April 2012, Ankara, MMO/588. ISBN 978-605-01-0358-8.

Tsabadze, T. 2006. A method for fuzzy aggregation based on group expert evaluations, Fuzzy Sets and Systems 10(157): 1346-1361. http://dx.doi.org/10.1016/j.fss.2005.11.015 
Tsoutsos, T.; Drandaki, M.; Frantzeskaki, N.; Iosifidis, E.; Kiosses, I. 2009. Sustainable energy planning by using multi-criteria analysis application in the island of Crete, Energy Policy 37: 1587-1600. http://dx.doi.org/10.1016/j.enpol.2008.12.011

Vahdani, B.; Hadipour, H. 2011. Extension of the ELECTRE method based on interval-valued fuzzy sets, Soft Computing 15(3): 569-579. http://dx.doi.org/10.1007/s00500-010-0563-5

Wang, J. J.; Jing, Y. Y.; Zhang, C. F.; Zhao, J. H. 2009. Review on multi-criteria decision analysis aid in sustainable energy decision-making, Renewable and Sustainable Energy Reviews 13: 2263-2278. http://dx.doi.org/10.1016/j.rser.2009.06.021

Wang, W.; Liu, X.; Qin, Y. 2012. Multi-attribute group decision making models under interval type-2 fuzzy environment, Knowledge-Based Systems 30: 121-128. http://dx.doi.org/10.1016/j.knosys.2012.01.005

Wang, Y. M.; Elhag, T. 2006. Fuzzy TOPSIS method based on alpha level sets with an application to bridge risk assessment, Expert Systems with Applications 31(2): 309-319. http://dx.doi.org/10.1016/j.eswa.2005.09.040

Wu, D.; Mendel, J. M. 2007a. Aggregation using the linguistic weighted average and interval type-2 fuzzy sets, IEEE Transactions On Fuzzy Systems 6(15): 1145-1161. http://dx.doi.org/10.1109/TFUZZ.2007.896325

Wu, D.; Mendel, J. M. 2007b. Uncertainty measures for interval type-2 fuzzy sets, Information Sciences 177(23): 5378-5393. http://dx.doi.org/10.1016/j.ins.2007.07.012

Wu, Z.; Chen, Y. 2007. The maximizing deviation method for group multiple attribute decision making under linguistic environment, Fuzzy Sets and Systems 14(158): 1608-1617. http://dx.doi.org/10.1016/j.fss.2007.01.013

Xu, P.; Chan, E. H. W. 2013. ANP model for sustainable Building Energy Efficiency Retrofit (BEER) using Energy Performance Contracting (EPC) for hotel buildings in China, Habitat International 37: 104-112. http://dx.doi.org/10.1016/j.habitatint.2011.12.004

Yu, C. S. 2002. A GP-AHP method for solving group decision-making fuzzy AHP problems, Computers \& Operations Research 29(14): 1969-2001. http://dx.doi.org/10.1016/S0305-0548(01)00068-5

Yuan, J. H.; Kang, J. G.; Zhao, C. H.; Hu, Z. G. 2008. Energy consumption and economic growth: evidence from China at both aggregated and disaggregated levels, Energy Economics 30: 3077-3094. http://dx.doi.org/10.1016/j.eneco.2008.03.007

Zadeh, L. 1965. Fuzzy sets, Information Control 8: 338-353. http://dx.doi.org/10.1016/S0019-9958(65)90241-X

Zadeh, L. A. 1975. The concept of a linguistic variable and its application to approximate reasoning-I, Information Sciences 8: 199-249. http://dx.doi.org/10.1016/0020-0255(75)90036-5

Zhou, P.; Ang, B. W.; Poh, K. L. 2006. Decision analysis in energy and environmental modeling: an update, Energy 31: 2604-2622. http://dx.doi.org/10.1016/0360-5442(95)00036-G

Abit BALIN, PhD and Research Assistant in Industrial Engineering Department at Yildiz Technical Unversity in Istanbul. He received the BS and MSc degrees in Industrial Engineering from Yildiz Technical Unversity. His main research interests are information technologies, MCDM methodologies, operations management, energy management and, optimal financial decisions.

Hayri BARACLI, PhD and Assistant Professor in Industrial Engineering Department at Yildiz Technical Unversity in Istanbul. He received the BS, MSc and PhD degrees in Industrial Engineering from Yildiz Technical Unversity. His main Research interests are quality management, transportation, financial management, operations management, optimal financial decisions. 